\title{
How Customs Control the Trade in Wildlife
}

\section{Ted Mouat}

In June last year a Customs officer at London Airport, suspicious of a cargo of 100 live royal pythons arriving from Ghana, checked the export permit with officials in Accra. They confirmed that the animals had been illegally exported from Ghana. The snakes were seized, and a difficult situation - what to do with 100 illegally imported live snakes? - was resolved by ffPS and the RSPCA jointly agreeing to pay the cost of returning the survivors to Ghana, where, under the guidance of ff PS Consultant, Dr Emmanuel Asibey, head of the Game and Wildlife Department, they were released in a national park. This incident highlights the important part the Customs Service plays in enforcing the Convention on International Trade in Endangered Species, and also some of the problems. Ted Mouat, who is a senior Customs official, describes how they are learning and coping, and how voluntary societies such as ffPS can help.

Most import prohibitions and restrictions are enforced through the Customs and Excise Acts, and this is true for wildlife. Where there is a breach of the law the goods, including animals and plants, are liable to seizure and the people involved to prosecution in the courts.

Import and, in some cases, export controls fall into two main categories. In the first, including those relating to plant and animal health, Customs refer breaches of the prohibition to the agency responsible for the restrictions for further action. In the second category, Customs are more closely and continuously involved and may themselves carry the case further - i.e. seize the goods and prosecute.

In enforcing the law it is a great help that today most people recognize the need for adequate controls on matters affecting the environment. Maintaining controls that are not considered necessary or desirable is, at best, difficult and, at worst, likely to be ineffective. The UK is often at the end or well along the distribution chain for endangered species. There is no doubt that effective controls can cut down the market available to the originating countries, but experience indicates that much remains to be done at the source. Many factors combine to make this difficult, and a major one is the economic need for the people in the originating countries to benefit from their indigenous wildlife. The contribution Customs can make to resolving the conflict between economic and environmental needs is limited, but contacts have been made with the environmental authorities in Ghana and Zimbabwe among others to discuss mutual problems.

Most Customs officers at ports and airports take a personal interest in endangered species legislation, but effectiveness depends on knowing which animal and plant species are protected and on being able to identify them. Customs officers are given basic information either by printed instructions or in a training course. More detailed advice is given to those operating at entry points where trade in endangered species is most common; they are often assisted by scien- 


\section{Specimens Seized by UK Customs under the Endangered Species Act 1976}

\begin{tabular}{crrl} 
& Seizures & \multicolumn{1}{c}{ Comprising } \\
1976 & 9 & 22 articles of parts and derivatives \\
1977 & 35 & 1030 articles of parts and derivatives \\
& 3 & 22 live birds \\
1978 & 8 & 90 cacti \\
& 46 & 4499 articles of parts and derivatives \\
& 2 & 11 live animals (other than birds) \\
1979 & 4 & 54 birds \\
& 123 & 4 cacti \\
1980 & 1 & 278 articles of parts and derivatives \\
& 493 & 6 live animals \\
1981 & 1 & 968 articles of parts and derivatives \\
(provisional & 1 & 2 live animals (other than birds) \\
figures) & 718 & 81 birds \\
& 9 & 1372 articles of parts and derivatives \\
& 2 & 297 live animals (other than birds) \\
& & 233 & live birds \\
& 11400 live plants (cyclamen)
\end{tabular}

tific colleagues in the Nature Conservancy Council (NCC) and voluntary bodies such as RSPB and ffPS. Some officers become very expert, but in legal proceedings it is unlikely that a court would accept a Customs officer as an expert witness on a scientific subject. So once an officer's 'antennae' start to twitch, he calls in the specialist. In conjunction with NCC and the Department of the Environment (DoE) Customs have built up a panel of experts who can be called upon, often at most inconvenient times when living specimens are involved. Inanimate objects can, of course, be held for later identification.

Most plants, all birds, most animals and some fishes are subject to some form of control for plant and animal health purposes, and these requirements must always be satisfied before they can be released by Customs. If the species is identified as one requiring an import licence and none is produced, several alternatives have to be considered. The specimen can be seized and the importer prosecuted. Here, much depends on the circumstances, including the advice given by DoE and NCC. Where the absence of a licence appears to be due to ignorance of the legal requirements, Customs can retain control of the specimen, if necessary at the importer's premises, while a licence is obtained. But if there appears to be a deliberate attempt to evade the controls, Customs investigate to establish whether their suspicions are justified and whether there is sufficient evidence to support a prosecution. In these cases seizure is invariable.

When living things are detained or seized there is the problem of where to put them. Plants are not difficult because the Royal Botanic Gardens, Kew, or someone recommended by them, can usually help. Animals are a different matter, especially those subject to quarantine. The only point of entry with permanent on-site facilities at present is London, Heathrow, where the Animal Quarantine Station is most helpful. But they cannot provide a long-term home, and sometimes it is necessary to turn to the department's zoo contacts to find a place, which may not be easy if large numbers are involved. Once animals are 
seized Customs becomes responsible for their care, and this can be expensive. For this reason the powers given in the 1981 Wildlife and Countryside Act to charge the importer with the cost of the animals' removal to a suitable place, or return to the wild, is very welcome. It is no benefit, of course, if the importer proves to have insufficient assets, but it does create an additional deterrent.

The Department is certain to play an increasing role in regulating the trade in endangered species, and experience will improve our effectiveness. This is also greatly helped by information and expertise from non-governmental organizations, such as ffPS. Customs are quick to acknowledge this fact and to express their appreciation of the support they receive from individuals and organizations with specialist knowledge of endangered species and the trade in them.

E.R.C. Mouat, HM Customs and Excise, Kent House, Upper Ground, London SE1 9PS.

\section{Otters in Ireland}

The otter Lutra lutra declined dramatically and rapidly in Britain, catching conservationists unawares and without the necessary information to remedy the situation. Very little was known about the otter population of Ireland but it became evident that the wetlands and coastal areas on which they depend are increasingly subject to the kinds of pressure which resulted in the otter declines of many European countries. On the recommendation of the Joint Otter Group a survey was carried out between 1980 and 1981 to establish the distribution of otters and to provide a baseline for future monitoring. Signs of otters were found in 91.7 per cent of the 2373 sites surveyed and no large areas were totally devoid of otters. As expected, polluted areas had fewer otters but, surprisingly, neither the presence of mink nor human disturbance in the urban areas seem to affect otter distribution, although their habits change with the degree of the latter. In the summer, when disturbance is at its maximum, they do not spraint on the riverside slipways and steps as they do in the winter, although they remain in the area. The results of the Otter Survey, published by the Vincent Wildlife Trust, are firm foundation for further monitoring. Hopefully this forward-looking step will lead to appropriate conservation measures to be taken when necessary and in time to secure the otters' future in Ireland.

\section{Hong Kong Turtle Imports}

In the last six months of 1981 Hong Kong imported $155,146 \mathrm{~kg}$ of freshwater turtles: $133,428 \mathrm{~kg}$ came from Bangladesh, and $21,718 \mathrm{~kg}$ from Thailand. Most weighed about $5 \mathrm{~kg}$, which means 26,000 turtles from Bangladesh and over 4000 from Thailand. The Chinese use large numbers of turtles for medicines and tonics and their demands are a significant drain on turtle populations of the Oriental region.

\section{Otters in Greece: A Correction}

The Editor greatly regrets that the key on the map illustrating the article 'Otters in Greece' in the last Oryx, Vol. XVI, No. 3, page 241, was incorrect. The correct version is that the solid black circles indicate positive stations; the open circles denote negative stations. 